\title{
Glutamate Receptors GluR1 and GluR4 in the Hamster Superior Colliculus: Distribution and Co-localization with Calcium-Binding Proteins and GABA
}

\author{
Jae-Sik Choi ${ }^{1}$, Jea-Young Lee ${ }^{1}$ and Chang-Jin Jeon ${ }^{1}$ \\ ${ }^{1}$ Department of Biology, College of Natural Sciences, Kyungpook National University, Daegu 702-701, South Korea
}

Received September 30, 2008; accepted January 7, 2009; published online March 31, 2009

\begin{abstract}
We investigated the distributions of AMPA glutamate receptor subtypes GluR1 and GluR4 in the hamster superior colliculus (SC) with antibody immunocytochemistry and the effect of enucleation on these distributions. We compared these labelings to those of GluR2/3 in our previous report (Park et al., 2004, Neurosci Res., 49:139-155) and calcium-binding proteins calbindin D28K, calretinin, parvalbumin, and GABA. Anti-GluR1-immunoreactive (IR) cells were scattered throughout the SC. By contrast, anti-GluR4-IR cells formed distinct clusters within the lower lateral stratum griseum intermediale (SGI) and lateral stratum album intermediale (SAI). The GluR1- and GluR4-IR neurons varied in size and morphology. The average diameter of the GluR1-IR cells was $13.00 \mu \mathrm{m}$, while the GluR4-IR cells was 20.00 $\mu \mathrm{m}$. The large majority of IR neurons were round or oval cells, but they also included stellate, vertical fusiform and horizontal cells. Monocular enucleation appeared to have no effect on the GluR1 and GluR4 immunoreactivity. Some GluR1-IR cells expressed calbindin D28K $(9.50 \%)$, calretinin $(6.59 \%)$, parvalbumin $(2.53 \%)$, and GABA $(20.54 \%)$. By contrast, no GluR4-IR cells expressed calcium-binding proteins or GABA. Although the function of the AMPA receptor subunits in SC is not yet clear, the distinct segregation of the GluR subunits, its differential colocalization with calcium-binding proteins and GABA, and differential responses to enucleation suggest the functional diversity of the receptor subunits in visuomotor integration in the SC.
\end{abstract}

Key words: AMPA glutamate receptors, calcium-binding proteins, GABA, immunocytochemistry, localization

\section{Introduction}

The mammalian superior colliculus (SC) plays an important role in orienting movements of the head and eyes. It is a highly laminated structure in the midbrain $[13,16,36]$. The three superficial layers (stratum zonale, SZ; stratum griseum superficiale, SGS; and stratum opticum, SO) receive visual information primarily from two sources: the retina and the visual cortex. The four deeper layers (stratum griseum intermediale, SGI; stratum album intermediale, SAI; stratum griseum profundum, SGP; and stratum album pro-

Correspondence to: Prof. Chang-Jin Jeon, Ph.D., Neuroscience Lab, Department of Biology, College of Natural Sciences, Kyungpook National Univ., 1370 Sankyuk-dong, Daegu, 702-701 S. Korea. E-mail: cjjeon@knu.ac.kr fundum, SAP) receive projections from many functionally different areas of the brain including visual, auditory, and somatosensory areas. One of the primary organizing characteristics of the $\mathrm{SC}$ is the topographical distribution of its afferent fibers and efferent cells. Many afferent fibers and efferent cells of the SC show horizontal, vertical or patchlike segregation in the SC $[7,13,14]$. An example is the laminar segregation of retinal and visual cortical inputs. Nearly $2 / 3$ of the retinotectal fibers are located in the upper SGS, while almost 3/4 of primary visual corticotectal fibers are located in the lower SGS [25]. A laminar segregation is also found in many neurochemical-containing neurons. For example, calbindin D28K-immunoreactive (IR) neurons are found in cells located in three tiers of the $\mathrm{SC}[1,22,29,30]$. The parvalbumin-IR neurons are concentrated in a dense tier within the deep SGS and upper SO and form complementary 
paternal distribution to that of calbindin D28K-containing neurons [5, 31]. Calretinin forms a dense plexus of IR fibers in the superficial layers of the SC $[12,21]$. Another example is the specific efferent cell clusters of tectofugal pathways. For example, neurons projecting to the cuneiform region formed clusters and were found to overlap precisely the acetylcholine patches in the SGI [19]. In addition, SC neurons projecting to the inferior olive formed clusters in the dorsal and ventral tiers of the SGI of the SC [13, 19].

Glutamate and its receptors play a crucial role in various cellular mechanisms. There are at least four forms of AMPA receptor subunits (GluR1-4) [11, 24]. The function of AMPA subunits is not clear yet, but the functional properties of glutamate receptors are determined by their subunit compositions. The GluR2 subunit plays a major role in the determination of the $\mathrm{Ca}^{2+}$ permeability of the receptors $[11$, 24].

There is substantial evidence regarding the presence of glutamate and AMPA receptors in the mammalian SC [6, $17,33,35]$. In the cat SC, there is a dense band of highly glutamate-IR neurons in the deep SGS and upper SO [17]. Glutamate is well-established as the excitatory neurotransmitter of retinotectal and corticotectal pathways $[2,18,27$, 28]. AMPA receptors have been observed at the postsynaptic sites in both the retinal and cortical afferents in the rat $[15,23]$, and cat SC [28]. AMPA receptors also exhibit laminar segregation. GluR2 has been identified in the SO of rat SC [20]. GluR2/3-IR cells formed a dense band of labeled cells within the lower SGS and upper SO in the cat SC, while GluR2/3-IR cells formed a dense band within the upper $\mathrm{SO}$ in the rabbit and within the $\mathrm{SO}$ in the hamster $\mathrm{SC}$ [32].

Previously, we reported the distributional pattern of GluR2/3 in hamster SC [32]. As the differences in the receptor subunit compositions are a key factor in understanding the distinct functional characteristics of the AMPA receptors in SC, we investigated the organization of GluR1- and GluR4-IR neurons in the present study. First, we examined the distribution and morphology of GluR1- and GluR4-IR neurons to determine if these receptor subtypes are localized in the specific lamina and specific cell types of hamster SC as this animal has been widely used for various anatomical and physiological studies of the SC. Second, we examined whether GluR1- and GluR4-IR neurons are specifically localized in subpopulations of calcium-binding proteins calbindin D28K-, calretinin-, and parvalbumin-IR neurons. Calcium-binding proteins are considered to actively work in calcium-mediated signal transduction [10, 34]. Third, we investigated whether GluR1- and GluR4-IR neurons also express GABA. It is well-known that great numbers of SC interneuron express GABA [26]. Finally, we investigated whether GluR1 and GluR4 immunoreactivities are affected by enucleation. We wanted to see if there were alterations of the numbers of GluR1- and GluR4-IR cells when reducing glutamate activity from retina through the enucleation.

\section{Materials and Methods}

\section{Animals}

Adult hamsters (8-10 weeks old; 20-30 g, n=9) were used in these experiments. The animals were divided into three groups. First, intact hamsters $(n=6)$ were used to determine the normal distribution of immunoreactivity to the AMPA receptor subunits GluR1 and GluR4, and to the calcium-binding protein calbindin D28K, calretinin, and parvalbumin, in the SC. Second, unilaterally $(n=3)$ enucleated animals were used to examine the effects of retinal deafferentation. Enucleation was performed under anesthesia with a mixture of ketamine hydrochloride (30-40 mg/kg) and xylazine (3-6 mg/kg), supplemented as needed to maintain anesthesia. The wound was then filled with sterile gelform to prevent bleeding. The enucleated animals were allowed to survive for 20 days. The National Institutes of Health guidelines for the use and care of animals were followed for all experimental procedures. All efforts were made to minimize animal suffering as well as the number of animals used.

\section{Perfusion and tissue processing}

All animals were anesthetized deeply with a mixture of ketamine hydrochloride $(30-40 \mathrm{mg} / \mathrm{kg})$ and xylazine (3-6 $\mathrm{mg} / \mathrm{kg}$ ) before perfusion. They were perfused transcardially with $4 \%$ paraformaldehyde and $0.3-0.5 \%$ glutaraldehyde in $0.1 \mathrm{M}$ sodium phosphate buffer $(\mathrm{pH}=7.4)$ with $0.002 \%$ calcium chloride added. Following a pre-rinse with approximately $30 \mathrm{ml}$ of phosphate-buffered saline (PBS, $\mathrm{pH}=7.2$ ) over a period of 1-4 min, each hamster was perfused with 30-50 $\mathrm{ml}$ of fixative for 5-10 min via a syringe needle inserted through the left ventricle and aorta. The head was then removed and placed in the fixative for $2-3 \mathrm{hr}$. The brain was removed from the skull, stored for $2-3 \mathrm{hr}$ in the same fixative, and left overnight in $0.1 \mathrm{M}$ phosphate buffer (PB, $\mathrm{pH}=7.4$ ) containing $8 \%$ sucrose and $0.002 \%$ calcium chloride. The blocks of midbrain were removed, mounted onto a chuck, and cut coronally into $50 \mu \mathrm{m}$ thick sections with a Vibratome. For three or four sections, two or three sections were used for immunocytochemistry and one was used for thionin. The thionin stained sections were used to identify the nuclei and collicular layers.

\section{Immunocytochemistry}

Polyclonal antibodies against GluR1 (AB 1504) and GluR4 (AB 1508), and a monoclonal antibody against GABA (MAB 316) were obtained commercially from Chemicon (Temecula, CA, USA). Monoclonal antibodies against calbindin D28K, calretinin, and parvalbumin were obtained from Sigma Chemical (St. Louis, MO, USA). The tissues were processed free floating in small vials. The primary antiserum was diluted at $1: 100$ to $1: 1000$ and incubated for $48 \mathrm{hr}$. For HRP immunocytochemistry, the biotinylated secondary antiserum was diluted at 1:200 and incubated for $2 \mathrm{hr}$. The immunocytochemical methods have been described in detail in our previous report [32]. As a 


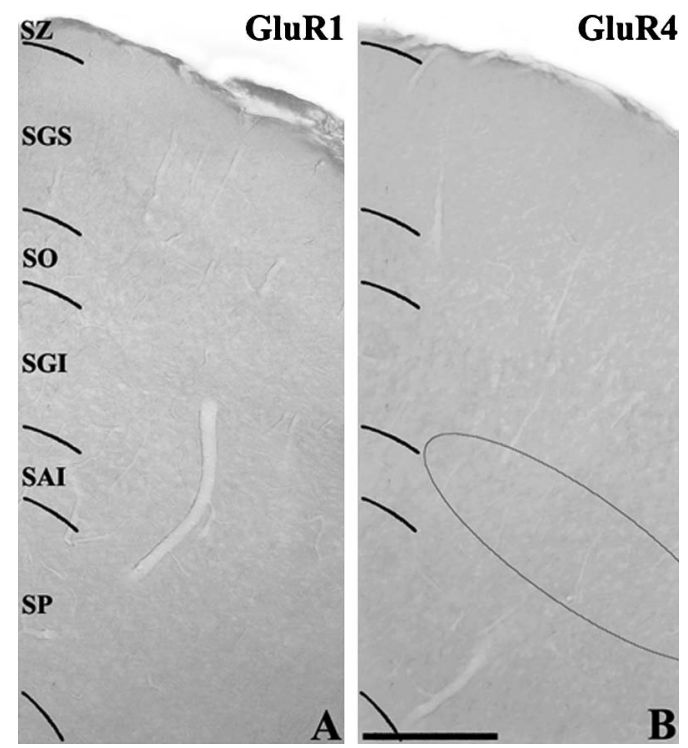

Fig. 1. Low power photomicrographs of control sections of the hamster SC used to show the specificity of GluR1 and GluR4 antibodies. The GluR1 (A) or GluR4 (B) antibody was preabsorbed with antigen prior to tissue incubation. The semicircle in (B) indicates area where GluR4-IR neurons are located (see Fig. 2C). Bar $=200 \mu \mathrm{m}$.

negative control, some sections were incubated in the same solution without the addition of the primary antibody. In addition, preabsorption of anti-GluR1 and GluR4 antibodies with the corresponding synthetic peptides (Chemicon, AG 360 for GluR1 and AG 306 for GluR4, $10 \mu \mathrm{g}$ of each peptide/ml, $12 \mathrm{hr}$ incubation at room temperature) was performed prior to tissue incubation. These control tissues showed no GluR immunoreactivity (Figs. 1A and B).

To generate two simultaneous labels, the sections were incubated in the primary antiserum using the appropriate steps described above. For detection by immunofluorescence, the secondary antibodies were fluorescein (FITC) conjugated anti-rabbit IgG (Vector Laboratories, Inc., Burlingame, CA, USA) to detect the anti-GluR1 and GluR4 antibody and Cy5 conjugated anti-mouse IgG (Jackson Immuno-Research Lab., West Grove, PA, USA) to detect the anti-calbindin D28K, calretinin, parvalbumin, or GABA antibody. For fluorescence immunocytochemistry, the secondary antiserum was diluted at 1:100 and incubated for $2 \mathrm{hr}$. The tissues were examined and photographed using a Zeiss Axioplan microscope or a Bio-Rad MRC 1024 laser scanning confocal microscope.

\section{Quantitative analysis}

The morphological types of GluR-IR cells were determined on DAB-reacted sections of normal animals. We estimated labeled cells in five sequential fields. Each field was positioned at approximately equal intervals. For the GluR1IR cells, the sequential fields, each $194 \mu \mathrm{m} \times 194 \mu \mathrm{m}$ in area, across the superior-inferior extent of the SC were centered in the middle SC. For the GluR4-IR cells, the sequential fields, across the medial-lateral extent of the SC were centered over the cluster of labeled neurons in the deep layer. The morphological types of GluR1-IR cells were determined from six different sections (two rostral, two middle, and two caudal sections) from each of two animals. We estimated about six hundred GluR1-IR cells. To match the number of GluR4-IR cells to that of GluR1-IR cells, we estimated GluR4-IR cells from eighteen sections (six rostral, six middle, and six caudal sections) of six normal animals. To obtain the best images, we analyzed cells under differential interference contrast (DIC) optics using 63X Zeiss Plan-Apochromat objectives. Only cell profiles containing nucleus and at least faintly visible nucleolus were included in this analysis. Soma diameters and areas GluR-IR cells were computed using Zeiss AxioVison (Ver. 4, Carl Zeiss) by circling the soma with a pen on the monitor.

To determine the double-labeled neurons of GluR with calcium-binding proteins or GABA, the sequential fields, each $303 \mu \mathrm{m} \times 303 \mu \mathrm{m}$ in area, across the superior-inferior extent of the SC were positioned in the medial (four), middle (five), and lateral (three) SC. Double-labeled neurons were counted from six different sections from each of two animals. Double-labeled images were obtained using a Bio-Rad MRC 1024 laser scanning confocal microscope using a 40X objective. The number of double-labeled cells was expressed as a percentage of the total populations of GluR1and GluR4-IR cells.

To compare the number of GluR1- and GluR4-IR cells of the normal SC, and ipsilateral and contralateral sides of the enucleated hamsters, we counted labeled cells in five sequential fields. For the GluR1-IR cells, the sequential fields, each $303 \mu \mathrm{m} \times 303 \mu \mathrm{m}$ in area, across the superior-inferior extent of the SC were centered in the middle SC. For the GluR4-IR cells, the sequential fields, across the mediallateral extent of the SC were centered over the labeled neurons in the clusters within the deep layer. The numbers of GluR-IR cells in normal SC were estimated from six different sections (two rostral, two middle, and two caudal sections) from each of four normal animals. The numbers of GluR-IR cells in enucleated SC were estimated from six different sections (two rostral, two middle, and two caudal sections) from each of three enucleated animals. We summed the numbers of labeled cells obtained in order to compare the normal, ipsilateral, and contralateral sides to the enucleation. The number of GluR-IR cells on the ipsilateral and contralateral sides to the enucleation was expressed as the percentage of labeled cells on the normal control side. The ratios were evaluated statistically by a Student's $t$-test between normal and ipsilateral, and contralateral sides to the enucleation.

\section{Results}

\section{Distribution of GluR1- and GluR4-IR neurons in the SC}

Figure 2A shows a thionin-stained section for collicular lamination while Figures $2 \mathrm{~B}-\mathrm{H}$ show GluR1 and GluR4 


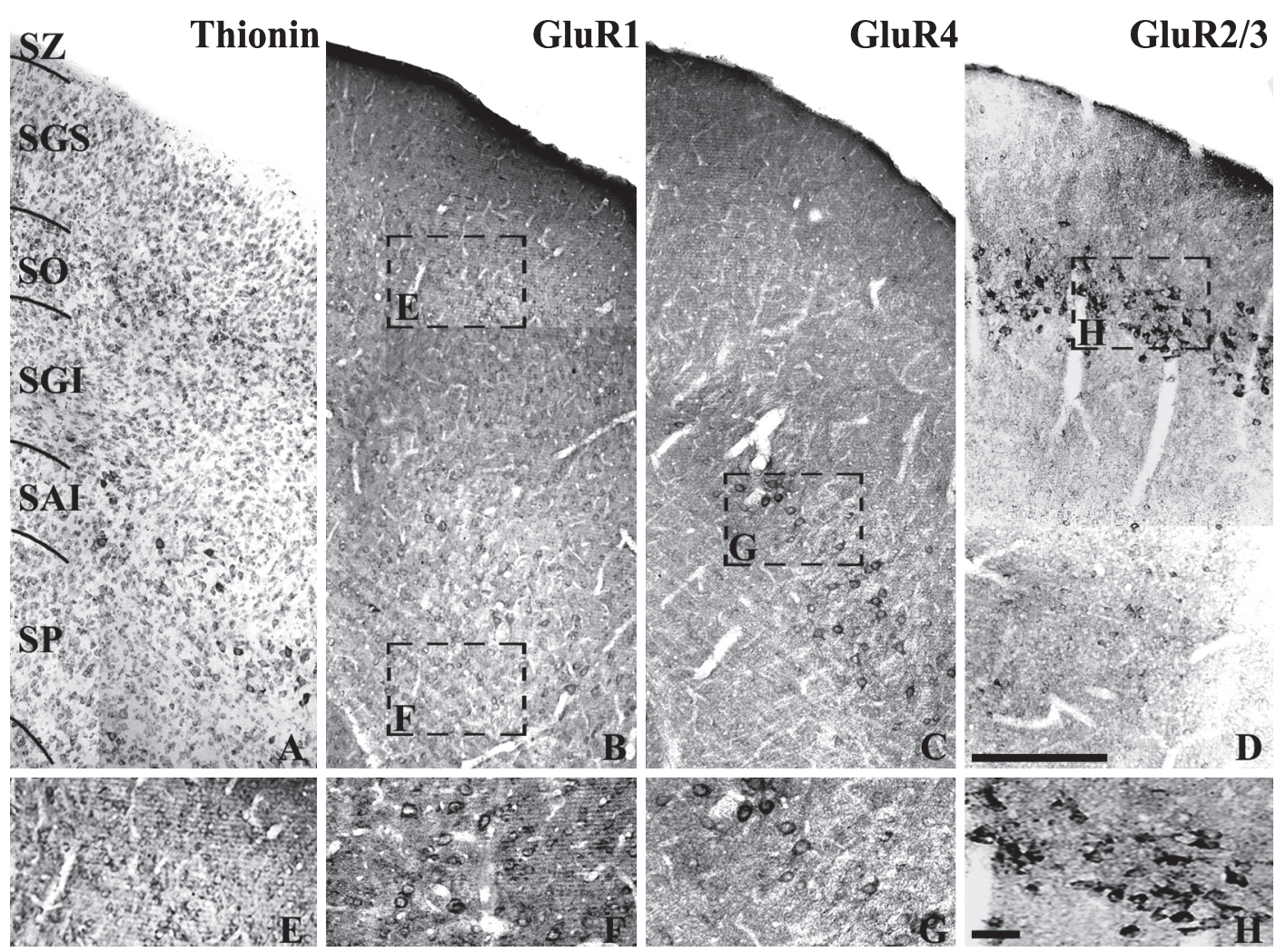

Fig. 2. Low power photomicrographs of the laminar distribution of AMPA subunits GluR1-, GluR2/3- and GluR4-IR neurons in the hamster SC. (A) Thionin-stained section showing the collicular lamination. (B) Anti-GluR1-immunoreactivity. GluR1-IR cells were distributed throughout the SC. (C) Anti-GluR4-immunoreactivity. GluR4-IR cells were selectively distributed in the lower lateral SGI and lateral SAI and formed clusters. (D) Anti-GluR2/3-immunoreactivity. As we previously reported (Park et al., 2004) GluR2/3-IR were concentrated within the SO and formed a dense band. Squares in (B-D). Indicate regions that are shown in higher magnification in $(\mathbf{E}-\mathbf{H})$. SAI, stratum album intermediale; SGI, stratum griseum intermediale; SGS, stratum griseum superficial; SP, stratum profundum; SO, stratum opticum; SZ, stratum zonale. $\operatorname{Bar}=200 \mu \mathrm{m}(\mathbf{A}-\mathbf{D})$ and $50 \mu \mathrm{m}(\mathbf{E}-\mathbf{H})$.

immunoreactivity in the hamster SC. The distributional patterns of anti-GluR1- and GluR4-IR cells in the present study were a great deal different from each other. GluR1-IR cells were found throughout the $\mathrm{SC}$ of the hamster (Fig. 2B, E and F). These cells did not show any specific laminar or cluster distribution. An almost equal density of labeled cells was observed throughout the SC. By contrast, GluR4-IR cells were very selectively distributed in the hamster SC (Fig. 2C and G). Figure 2C shows that anti-GluR4 immunoreactivity in the normal hamster SC was distinctively located within the lower SGI and SAI and formed clusters. This cluster of highly GluR4-IR cells could be seen throughout the rostral-caudal extent of the SC. The thickness of this cluster was approximately $200 \mu \mathrm{m}$ wide from the central portion, and approximately $600-800 \mu \mathrm{m}$ long from the mid-colliculus. By contrast, very few labeled cells were seen in the other layers. As we previously reported [32], GluR2/3-IR cells were very selectively distributed and formed a dense band within the SO (Fig. 2D and H).

\section{Morphology of the anti-GluR1-and GluR4-IR neurons}

GluR1- and GluR4-IR neurons varied both in size and morphology. The majority of GluR1-IR cells had small- to medium-sized cell bodies. The average diameter of 602 GluR1-IR cells measured in 6 sections from 2 animals ranged from 9.03 to $24.57 \mu \mathrm{m}$ with a mean of $13.00 \mu \mathrm{m}$ (Fig. 3A). The vast majority ( $83.22 \%$ or 501 of 602 cells) of GluR1-IR neurons were small-sized $(<15.00 \mu \mathrm{m})$ with a few (1.16\% or 7 of 602 cells) exceeding $20.00 \mu \mathrm{m}$ in diameter. The average area of 602 GluR1-IR cells ranged from $60.18-$ $461.92 \mu \mathrm{m}^{2}$ with a mean of $116.80 \mu \mathrm{m}^{2}$ (Fig. 3B). The majority of GluR4-IR cells, however, had medium- to largesized cell bodies. The average diameter of 615 GluR4-IR cells measured in 18 sections from 2 animals ranged from 16.63 to $25.78 \mu \mathrm{m}$ with a mean of $20.00 \mu \mathrm{m}$ (Fig. 3A). More than half $(55.61 \%$ or 342 of 615 cells $)$ of the labeled cells were large-sized $(>20.00 \mu \mathrm{m})$ with no small cells below $15.00 \mu \mathrm{m}$. The average area of the GluR4 cells ranged from 217.12 to $510.50 \mu \mathrm{m}^{2}$ with a mean of $302.60 \mu \mathrm{m}^{2}$ (Fig. 3B).

The principal neuronal type in the hamster SC labeled with antibody to GluR1 was round or oval cells. The staining of GluR1, however, was also robust in other types of neurons. Figure 4A shows small- to medium-sized round or oval cells. These cells usually possessed a single large dendritic 

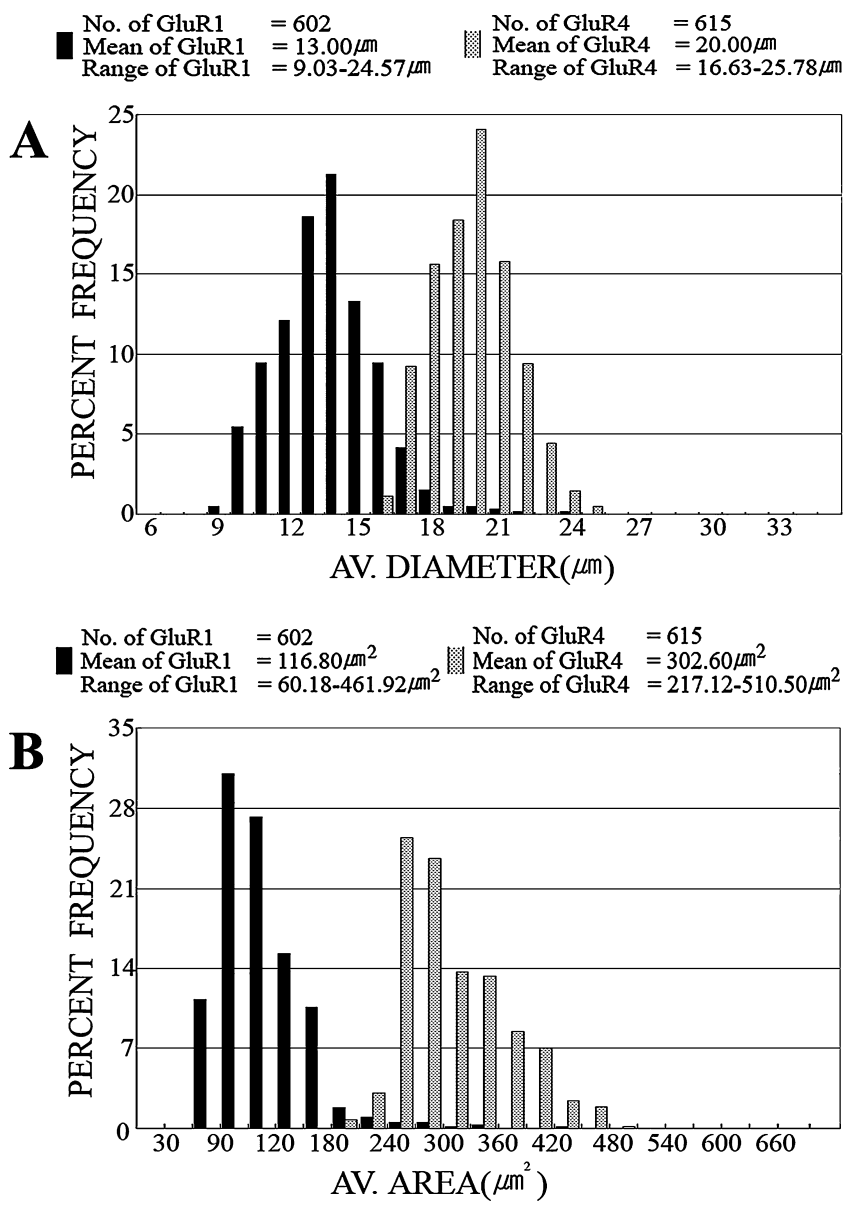

Fig. 3. Frequency distributions of (A) average diameter and (B) average area of 602 and 615 neurons labeled by anti-GluR1 and anti-GluR4 antibodies, respectively. The mean average diameter of GluR1-IR cells was $13.00 \mu \mathrm{m}$; the mean average area was 116.80 $\mu \mathrm{m}^{2}$. The mean average diameter of GluR4-IR cells was $20.00 \mu \mathrm{m}$; the mean average area was $302.60 \mu \mathrm{m}^{2}$. stump emanating from the cell body. Figure 4B shows a stellate neuron with a stellate-shaped cell body. However, horizontal cells (Fig. 4C) with horizontal fusiform cell bodies and horizontally oriented processes and vertical fusiform cells (Fig. 4D, arrowhead) with a thick, proximal dendritic stump directed towards the pial surface were also found. Quantitatively, 70.27 $\pm 3.82 \%$ (mean \pm S.D.) (423 of 602 cells) of anti-GluR1 labeled neurons were round or oval, $19.76 \pm 1.63 \%$ (119 of 602 cells) were stellate, $7.31 \pm 1.21 \%$ (44 of 602 cells) were horizontal, and $2.66 \pm 1.11 \%$ (16 of 602 cells) were vertical fusiform neurons.

The two principal neuronal types in the hamster SC labeled with antibody to GluR4 were round or oval cells and stellate cells. The staining of GluR4, however, was also robust in other types of neurons. The first morphological type consisted of medium- to large-sized round or oval cells. Figure 4E shows representative medium-sized round or oval cells. The second one consisted of medium- to large-sized stellate cells. Figure 4F shows a representative large-sized stellate cell. Stellate cells had stellate-shaped cell bodies with dendrites which extended in multiple directions. However, horizontal cells (Fig. 4G) with horizontal fusiform cell bodies and horizontally oriented processes and vertical fusiform cells (Fig. 4H) with a thick, proximal dendritic stump directed towards the pial surface were also found. Quantitatively, $62.43 \pm 2.97 \%$ (mean \pm S.D.) (384 of 615 cells) of antiGluR4 labeled neurons were round or oval, $28.46 \pm 2.58 \%$ (175 of 615 cells) were stellate, $6.83 \pm 1.41 \%$ (42 of 615 cells) were horizontal, and $2.28 \pm 1.29 \%$ (14 of 615 cells) were vertical fusiform neurons.

\section{Effect of monocular enucleation on GluR1 and GluR4 expression}

To determine whether enucleation affects the distribution of the GluR1- and GluR4-IR cells in the hamster SC, we performed monocular enucleation in three animals. Enucle-
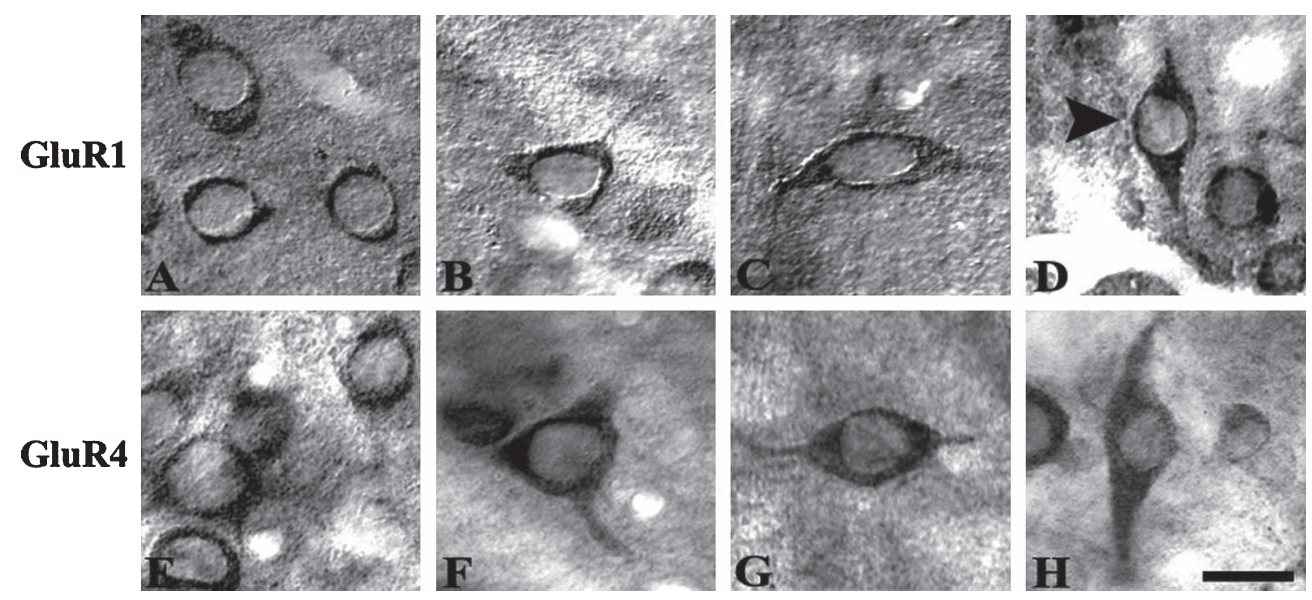

Fig. 4. High-magnification of differential interference contrast micrographs of GluR1- (A-D) and GluR4-IR (E-H) cells in the hamster SC. (A, E) Small- to medium-sized round or oval neurons. (B, F) A medium-sized $(\mathbf{B})$ and a large-sized (F) stellate neurons. $(\mathbf{C}, \mathbf{G})$ Horizontal cells with horizontally oriented dendrites. (D, H) Vertical fusiform neurons (arrowhead) with proximal dendrite projecting superficially toward the pial surface. Bar $=20 \mu \mathrm{m}$. 
Table 1. Changes in the number of GluR1- and GluR4-IR neurons in the hamster SC after monocular enucleation

\begin{tabular}{|c|c|c|c|c|c|}
\hline SC sides & Animal No. & No. Sections & No. GluR1 & No. Sections & No. GluR4 \\
\hline \multirow{6}{*}{ Normal SC } & N-Hamster 1 & 3 & 1261 & 6 & 324 \\
\hline & N-Hamster 2 & 3 & 1295 & 6 & 332 \\
\hline & N-Hamster 3 & 3 & 1274 & 6 & 328 \\
\hline & N-Hamster 4 & 3 & 1304 & 6 & 327 \\
\hline & Total & 12 & 5134 & 24 & 1311 \\
\hline & (Mean \pm S.D) & & $1283.5 \pm 19.57$ & & $327.75 \pm 3.30$ \\
\hline \multirow{6}{*}{ Enucleated ipsilateral SC } & E-Hamster 1 & 3 & 1266 & 6 & 322 \\
\hline & E-Hamster 2 & 3 & 1285 & 6 & 326 \\
\hline & E-Hamster 3 & 3 & 1305 & 6 & 327 \\
\hline & Total & 9 & 3856 & 18 & 975 \\
\hline & (Mean \pm S.D) & & $1285.33 \pm 19.5$ & & $325.00 \pm 4.60$ \\
\hline & $\%$ change & & $0.14 \%$ & & $-0.83 \%$ \\
\hline \multirow{6}{*}{ Enucleated contralateral SC } & E-Hamster 1 & 3 & 1282 & 6 & 332 \\
\hline & E-Hamster 2 & 3 & 1298 & 6 & 328 \\
\hline & E-Hamster 3 & 3 & 1316 & 6 & 313 \\
\hline & Total & 9 & 3896 & 18 & 973 \\
\hline & (Mean \pm S.D) & & $1298.66 \pm 17.00$ & & $324.33 \pm 3.51$ \\
\hline & $\%$ change & & $1.18 \%$ & & $-1.04 \%$ \\
\hline
\end{tabular}

N, Normal; E, Enucleation

ation appeared to have no effect on the distribution of both the GluR1- and GluR4-IR cells on the contralateral experimental SC compared to the normal SC after unilateral enucleation (Table 1). Quantitatively, GluR1-IR cells showed no significant change in IR cell number; $0.14 \%(P=0.41)$ on the ipsilateral SC $(1285.33 \pm 19.50$ cells, mean \pm S.D. $)$, and $1.18 \%(P=0.74)$ on the contralateral SC $(1298.66 \pm 17.00$ cells) compared to the normal SC $(1283.50 \pm 19.57$ cells $)$. Quantitatively, GluR4-IR cells showed no significant change in the IR cell number, either; $-0.83 \%(P=0.31)$ on the ipsilateral SC (325.00 \pm 4.60 cells $)$, and $-1.04 \%(P=0.75)$ on the contralateral SC $(324.33 \pm 3.51$ cells $)$ compared to the normal SC (327.75 \pm 3.30 cells).

\section{Co-localization with GluR1 or GluR4, and calbindin D28K, calretinin, parvalbumin or GABA immunoreactivity}

To determine whether the GluR1- or GluR4-IR cells in the hamster SC co-localize with calbindin D28K, calretinin, parvalbumin, or GABA, we labeled GluR1 or GluR4 with fluorescein and calbindin D28K, calretinin, parvalbumin, or GABA with Cy5. Some cells were clearly labeled by both GluR1 and calbindin D28K, calretinin, parvalbumin, or GABA antibodies in the hamster SC (Fig. 5, arrowheads). Other cells were labeled by one of the antibodies, but not by both. There was no obvious relationship between cell morphology and whether the cell was single- or double-labeled. To estimate the percentage of double-labeled cells of GluRIR cells, we counted the numbers of GluR-IR cells and double-labeled cells across the SC from six different sections from each of two animals. A quantitative histogram reveals the proportion of colocalization between GluR1 and calcium-binding proteins (Fig.6). Quantitatively,
$9.50 \pm 1.10 \%$ (mean \pm S.D.) of the GluR1-IR cells were double-labeled with calbindin D28K (397 of 4179 cells), $6.59 \pm 1.09 \%$ of the GluR1-IR cells were double-labeled with calretinin (287 of 4356 cells), $2.53 \pm 1.40 \%$ of the GluR1-IR cells were double-labeled with parvalbumin (105 of 4147 cells), and $20.54 \pm 2.01 \%$ of the GluR1-IR cells were double-labeled with GABA (825 of 4017 cells). This percentage of double-labeled cells was relatively consistent across sections and among animals. By contrast, none of the GluR4-IR cells were double-labeled with calbindin D28K, calretinin, parvalbumin, or GABA (Fig. 7).

\section{Discussion}

The present study has revealed several important features of the hamster SC: 1) the distributional pattern of GluRs is very different among different subunits; 2) coexpression of GluR1 and GluR4 with calcium-binding proteins or GABA is also very different; 3 ) the numbers of GluR1 - and GluR4-IR neurons were not changed by enucleation.

With respect to the distribution, at least one solid conclusion can be drawn from the present and our previous data [32]. Differences in the pattern of distribution among different AMPA subunits are clearly seen in SC. GluR2/3-IR cells formed a dense band within the SO of the hamster SC [32]. However, the distribution of GluR1 and GluR4 is strikingly different from GluR2/3 in the present study. Differences in specialization of the distribution of the AMPA subunits also exist between animals. In contrast to the present result of GluR1, most GluR1 mRNA and GluR1 immunoreactivity were weakly detected in the superficial layers of the rat SC 

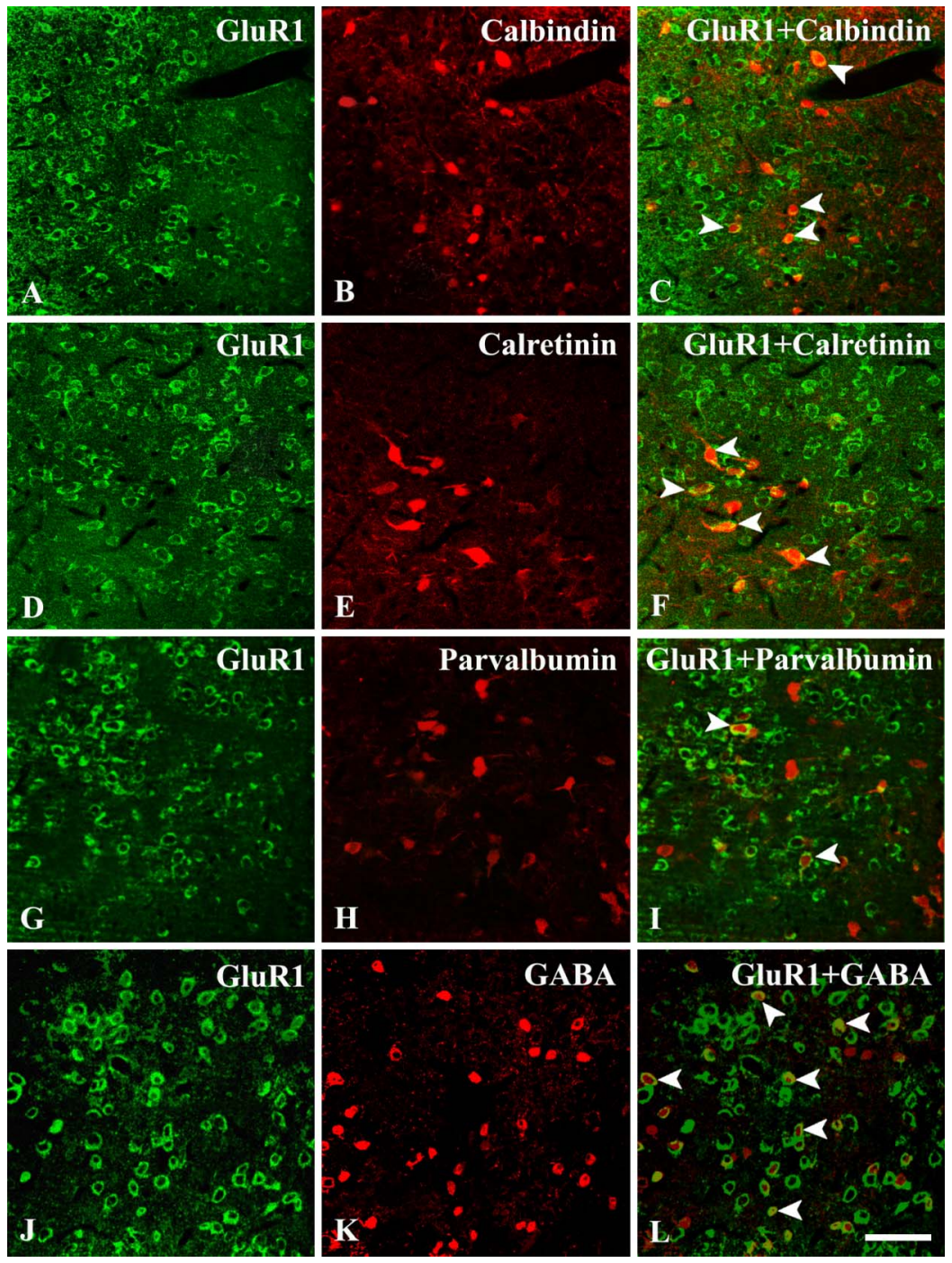

Fig. 5. Fluorescence confocal photomicrographs of the hamster SC immunostained for GluR1 (A, D, G, J) and calbindin D28K from SGS (B), calretinin from SAI (E), parvalbumin from SGS $(\mathbf{H})$, or GABA from SGS $(\mathbf{K})$. (C, F, I, L) Superimposition of images in GluR1 and calbindin D28K $(\mathbf{C})$, calretinin $(\mathbf{F})$, parvalbumin $(\mathbf{I})$, or GABA $(\mathbf{L})$. Some cells (arrowheads) were clearly labeled by both antibodies in the hamster SC. $\mathrm{Bar}=20 \mu \mathrm{m}$.

[20]. Our previous study also demonstrated that the organizational feature of the GluR2/3 found in the cat, rabbit, and hamster SC was strikingly different among the species [32]. A heterogeneous distribution of AMPA receptor subunits also has been observed in the avian optic tectum, the comparable area of the SC of non-mammalian vertebrates. Thus, GluR1-IR neurons were located to the layers $2-5,9,10$, and 13. GluR2/3-IR neurons were located to the layers 9,10 , and 13. However, no GluR4-IR neurons were located in the optic tectum [37]. These combined results indicate that there are considerable subunits and species differences in the distribution of GluRs in the SC. The functional significance of the remarkable different laminar distributional pattern of GluRIR neurons and interspecies differences is not clear yet.

The present study provides crucial information on the characteristic positions of neurochemically-specific SC cells. Along with results on the laminar segregation of

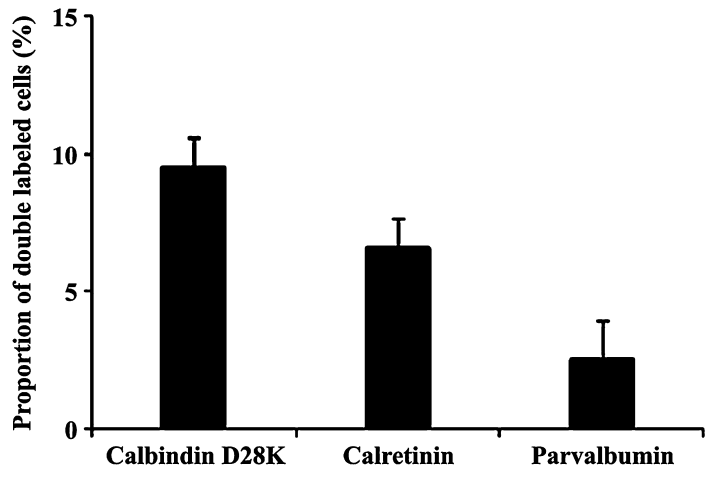

Fig. 6. Histogram of the proportion of colocalization between GluR1 and calbindin D28K, calretinin, or parvalbumin in hamster SC. Only small percentage of GluR1-IR neurons is correlated with the expression of calcium-binding proteins. 

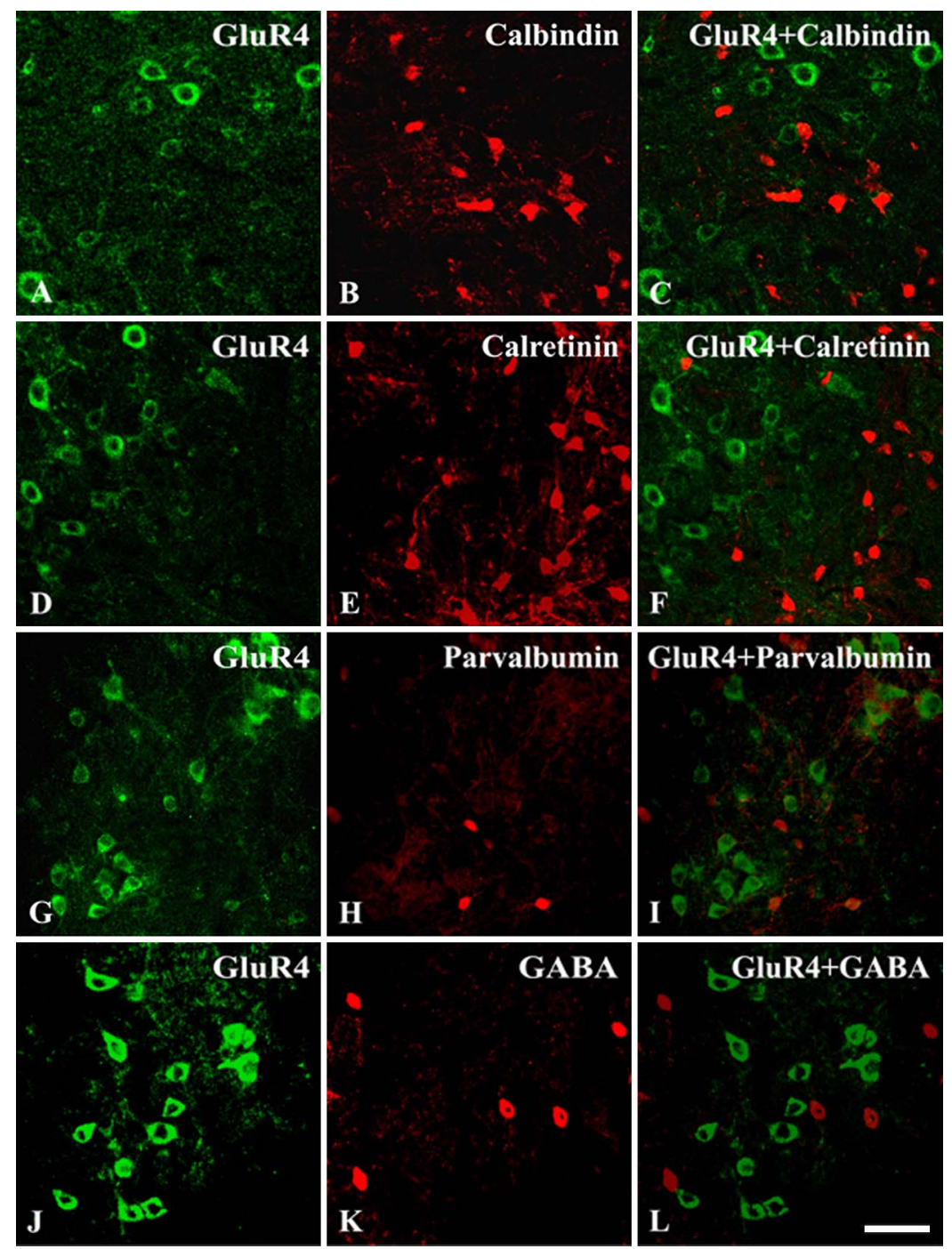

Fig. 7. Fluorescence confocal photomicrographs of the hamster SC immunostained for GluR4 (A, D, G, J) and calbindin D28K from lower SGI (B), calretinin from SAI (E), parvalbumin from lower SGI (H), or GABA from lower SGI (K). (C, F, I, L) Superimposition of images in GluR4 and calbindin D28K $(\mathbf{C})$, calretinin $(\mathbf{F})$, parvalbumin $(\mathbf{I})$, or GABA $(\mathbf{L})$. None of the cells was clearly labeled by both antibodies in the hamster SC. $\mathrm{Bar}=20 \mu \mathrm{m}$.

GluR2/3 in the SO [32], we demonstrated that GluR4-IR cells form a cluster of labeled neurons in the lower lateral SGI and lateral SAI in the present study. One of the characteristic features of $\mathrm{SC}$ is that its somas are located within specific domains of the SC [7, 13]. For example, neurons projecting to the inferior olive are located in clusters within the dorsal and ventral tiers of SGI $[13,19]$. Jeon and Mize (1993) demonstrated that neurons projecting to the cuneiform nucleus are located in clusters within the SGI, and observed these neurons that project to the cuneiform nucleus in the SC lie within the acetylcholine-rich patches. Moreover, these neurons are possibly related with saccadic eye movement. The lower SGI and SAI receive functional information from many brain areas including cortical areas such as anterior ectosylvian sulcus, anterior lateralsylvian area, dorsolateral suprasylvian area, and periauditory area [8]. The lower SGI and SAI also receive patch-like input from inferior colliculus, substantia nigra, and hypothalamus [7, 9, 13]. Thus, it is possible that the GluR4-IR cell clusters which are characteristically positioned in the lower SGI and SAI may reflect specific functional domains such as for the generation of orienting movement in hamster SC.

With respect to the effect of enucleation, we can also draw at least one solid conclusion from the present and our previous data [32]. Differences in the manner of distribution among different GluR subunits are clearly seen after enucleation in hamster SC. The retinotectal fibers are known to project to the superficial layers [13]. A previous study showed that AMPA-binding was significantly reduced in the rat SC after enucleation [3]. Kondo et al. (2000) found a lower expression of GluR2 mRNA and GluR2/3 immunoreactivity in the contralateral rat SC after enucleation. Our lab 
also demonstrated that immunoreactivity for the GluR2/3 was clearly reduced $(35.8 \%)$ in the contralateral SC following unilateral enucleation in the hamster. Thus, it is very likely that other subunits of AMPA could be affected by enucleation. Contrary to our presumption, enucleation appeared to have had no effect on the GluR1- and GluR4-IR cells of the hamster SC in the present study. It is not surprising that GluR4-IR cells are not affected by enucleation as GluR4-IR cells are located in the deep layers where retinotectal fibers do not make direct terminals [13]. However, it is surprising that GluR1-IR cells, located numerously in the superficial layers, are not affected by enucleation. Although there are many GluR1-IR cells in the superficial layers, our results suggest that GluR1-IR cells in the superficial layers may receive other major inputs such as the visual cortex. It is not known whether the effect of enucleation on the GluRs is animal specific or not. A previous study showed that the phenomenon on reduction of GluR2/3-IR cells in the hamster and rat were substantially different from those in the cat and rabbit. We found no evidence that enucleation affects GluR2/3 immunoreactivity in the cat and rabbit SC [32]. Thus, there are considerable animal variations. It will be necessary to investigate the effect of GluR1- and GluR4-IR cells in other laboratory animals such as the cat and rabbit.

A notable feature of GluRs-expressing neurons in the hamster SC in the present study is that there were marked differences in the expression of calbindin D28K, calretinin or parvalbumin in the GluRs-IR cells. We showed that some GluR1-IR neurons co-expressed calcium-binding proteins, while none of the GluR4-IR neurons co-expressed these proteins. By contrast, more than half of the GluR2/3-IR neurons in the hamster SC co-expressed calbindin D28K [32]. Clearly, the differential co-localization ratio of GluRs with calcium-binding proteins indicates that GluR-activated downstream pathways in postsynaptic neurons in hamster SC should be diverse and may have different susceptibility to glutamate excitocytotoxicity [4]. The existence of calciumbinding proteins in GluR1 - and GluR2/3-IR neurons may indicate that many of the GluR1- and GluR2/3-IR neurons in the hamster SC are protected from calcium-overflowing excitotoxic injury while many of the GluR4-IR neurons are more susceptible to calcium-overflowing excitotoxic injury. However, it is worthy to note that there are regional and species differences in calcium-binding protein expressing GluRs-containing neurons. For example, GluR2/3-IR cells express calbindin $\mathrm{D} 28 \mathrm{~K}$ in cat and hamster SC, while none of the GluR2/3-IR cells in rabbit SC co-expressed calbindin D28K [32]. GluR2/3-IR cells express parvalbumin in cat $\mathrm{SC}$, while none of the GluR2/3-IR cells in rabbit and hamster SC co-expressed parvalbumin. These results emphasize the neurochemical diversity of animal species. The questions on the functional significance on the complex regional and species differences in calcium-binding protein expressing GluRs-containing neurons should be carried out in the future.

The exact function of AMPA subunits in SC remains unclear. However, the different compartmental organization of AMPA subunits may be associated with functionally different neuronal pathways. Neurons in the superficial layers are concerned with vision, while the deeper SC play a role in integrating sensory information into motor signals that help orient the head toward various stimuli and play an important role in saccadic eye movements $[13,15,36]$. The present results suggest that the GluR4-IR cells in the deep layers may be associated with multisensory inputs from cortical or subcortical areas that are concerned with the generation of head, eye, and ear movements. However, the distributional pattern of GluR1-IR cells in the present study suggests that GluR1IR cells may receive both visual inputs and multisensory inputs from many central nervous systems. On the contrary, our previous results suggest that GluR2/3-IR cells in the SO are mainly associated with visual input from the retina or visual cortical areas that are concerned exclusively with the processing of visual information. The validity of these assumptions should be verified by physiological studies in the future.

In conclusion, the present study demonstrates the organizational patterns of GluR1- and GluR4-IR cells in the hamster SC. Together with the distribution of GluR2/3-IR cells in SO of hamster SC, all GluRs revealed a characteristic distributional pattern. The labeled neurons were heterogeneous in size and shape. Monocular enucleation appeared to have no significant effect on the GluR1 and GluR4 immunoreactivity. Some GluR1-IR cells also expressed calciumbinding proteins or GABA, while no GluR4-IR cells expressed calcium-binding proteins or GABA. Further studies are needed to investigate the functional significance of the variations observed among the different subunits.

\section{Acknowledgments}

We thank Dr. Paul William Clark for proofreading the paper. This work was supported by a Grant (R01-2003-00010505-0) from the Basic Research Program of the Korea Science and Engineering Foundation.

\section{References}

1. Behan, M., Jourdain, A. and Bray, G. M. (1992) Calcium-binding protein (calbindin D28K) immunoreactivity in the hamster superior colliculus: ultrastructure and lack of co-localization with GABA. Exp. Brain Res. 89; 115-124.

2. Binns, K. E. (1999) The synaptic pharmacology underlying sensory processing in the superior colliculus. Prog. Neurobiol. 59; 129-159.

3. Chalmers, D. T. and McCulloch, J. (1991) Selective alterations in glutamate receptor subtypes after unilateral orbital enucleation. Brain Res. 540; 255-265.

4. Choi, D. W. (1988) Glutamate neurotoxicity and disease of the nervous system. Neuron 1; 623-634.

5. Cork, R. J., Baber, S. Z. and Mize, R. R. (1998) Calbindin D28Kand parvalbumin-immunoreactive neurons form complimentary sublaminae in the rat superior colliculus. J. Comp. Neurol. 394; 205-217.

6. Endo, T. and Isa, T. (2001) Functionally different AMPA-type glutamate receptors in morphologically identified neurons in rat 
superior colliculus. Neuroscience $108 ; 129-141$

7. Harting, J. K. (2004) Puffs and patches: a brief chronological review. ed. by Hall, W. C. and Moschovakis, A., CRC Press, Bocaraton, pp. 83-105.

8. Harting, J. K., Updyke, B. V. and Van Lieshout, D. P. (1992) Corticotectal projections in the cat: anterograde transport studies of twenty-five cortical areas. J. Comp. Neurol. 324; 379-414.

9. Harting, J. K. and Van Lieshout, D. P. (2000) Projections from the rostral pole of the inferior colliculus to the cat superior colliculus. Brain Res. 27; 244-247.

10. Heizmann, C. W. and Braun, K. (1995) Calcium Regulation by Calcium-Binding Proteins in Neurodegenerative Disorders, Springer-Verlag, New York.

11. Hollmann, M. and Heinemann, S. (1994) Cloned glutamate receptors. Annu. Rev. Neurosci. 17; 31-108.

12. Hong, S. K., Kim, J. Y. and Jeon, C. J. (2002) Immunocytochemical localization of calretinin in the superficial layers of the cat superior colliculus. Neurosci. Res. 44; 325-335.

13. Huerta, M. F. and Harting, J. K. (1984) The mammalian superior colliculus: studies of its morphology and connections. Ed. By H. Vangega, Plenum Press, New York, pp. 687-772.

14. Illing, R. B. (1996) The mosaic architecture of the superior colliculus. Prog. Brain Res. 112; 17-34.

15. Isa, T., Endo, T. and Saito, Y. (1998) The visuo-motor pathway in the local circuit of the rat superior colliculus. J. Neurosci. 18; 8496-8504.

16. Isa, T. and Sasaki, S. (2002) Brainstem control of head movements during orienting; organization of the premotor circuit. Prog. Neurobiol. 66; 205-241.

17. Jeon, C. J., Gurski, M. R. and Mize, R. R. (1997) Glutamate containing neurons in the cat superior colliculus revealed by immunocytochemistry. Vis. Neurosci. 14; 387-393.

18. Jeon, C. J., Hartman, M. K. and Mize, R. R. (1997) Glutamatelike immunoreactivity in the cat superior colliculus and visual cortex: further evidence that glutamate is the neurotransmitter of the corticocollicular pathway. Vis. Neurosci. 14; 27-37.

19. Jeon, C. J. and Mize, R. R. (1993) Choline acetyltransferaseimmunoreacitive patches overlap specific efferent cell groups in the cat superior colliculus. J. Comp. Neurol. 337; 127-150.

20. Kondo, M., Sumino, R. and Okado, H. (2000) Expression of AMPA receptors in rat superior colliculus and effect of orbital enucleation. Brain Res. 883; 238-242.

21. Lee, J. Y., Choi, J. S., Ahn, C. H., Kim, I. S., Ha, J. H. and Jeon, C. J. (2006) Calcium-binding protein calretinin immunoreactivity in the dog superior colliculus. Acta Histochem. Cytochem. 39; $125-138$

22. Lee, J. Y., Choi, J. S., Ye, E. A., Kim, H. H. and Jeon, C. J. (2007) Organization of calbindin D28K-immunoreactive neurons in the dog superior colliculus. Zoolog. Sci. 24; 1103-1114.

23. Lo, F. S., Cork, R. J. and Mize, R. R. (1998) Physiological properties of neurons in the optic layer of the rat's superior colliculus. J. Neurophysiol. 80; 331-343.
24. Michaelis, E. K. (1998) Molecular biology of glutamate receptors in the central nervous system and their role in excitotoxicity, oxidative stress and aging. Prog. Neurobiol. 54; 369-415.

25. Mize, R. R. (1983) Patterns of convergence and divergence of retinal and cortical synaptic terminals in the cat superior colliculus. Exp. Brain Res. 51; 88-96.

26. Mize, R. R. (1992) The organization of GABAergic neurons in the mammalian superior colliculus. Prog. Brain Res. 90; 219 248.

27. Mize, R. R. and Butler, G. D. (1996) Postembedding immunocytochemistry demonstrates directly that both retinal and cortical terminals in the cat superior colliculus are glutamate immunoreactive. J. Comp. Neurol. 371; 633-648.

28. Mize, R. R. and Butler, G. D. (2000) The NMDAR1 subunit of the N-methyl-D-aspartate receptor is localized at postsynaptic sites opposite both retinal and cortical terminals in the cat superior colliculus. Vis. Neurosci. 17; 41-53.

29. Mize, R. R., Jeon, C. J., Butler, G. D., Luo, Q. and Emson, P. C. (1991) The calcium-binding protein calbindin-D28K reveals subpopulations of projection and interneurons in the cat superior colliculus. J. Comp. Neurol. 307; 417-436.

30. Mize, R. R. and Luo, Q. (1992) Visual deprivation fails to reduce calbindin $28 \mathrm{kD}$ or GABA immunoreactivity in the rhesus monkey superior colliculus. Vis. Neurosci. 9; 157-168.

31. Mize, R. R., Luo, Q., Butler, G., Jeon, C. J. and Nabors, B. (1992) The calcium-binding proteins parvalbumin and calbindin-D28K form complementary patters in the cat superior colliculus. $J$. Comp. Neurol. 320; 243-256.

32. Park, W. M., Kim, M. J. and Jeon, C. J. (2004) Ionotropic glutamate receptor GluR2/3-immunoreacitive neurons in the cat, rabbit, and hamster superficial superior colliculus. Neurosci. Res. 49; 139-155.

33. Petralia, R. S. and Wenthold, R. J. (1992) Light and electron immunocytochemical localization of AMPA-selective glutamate receptors in the rat brain. J. Comp. Neurol. 318; 329-354.

34. Polans, A., Baehr, W. and Palczewski, K. (1996) Turned on by $\mathrm{Ca}^{2+}$ ! The physiology and pathology of $\mathrm{Ca}^{2+}$-binding proteins in the retina. Trends Neurosci. 19; 547-554.

35. Sato, K., Kiyama, H. and Tohyama, M. (1993) The differential expression patterns of messenger RNAs encoding non-N-methylD-aspartate glutamate receptor subunits (GluR1-4) in the rat brain. Neuroscience 52; 515-539.

36. Sparks, D. L. (1999) Conceptual issues related to the role of the superior colliculus in the control of gaze. Curr. Opin. Neurobiol. 9; 698-707.

37. Theiss, C., Hellmann, B. and Güntürkün, O. (1998) The differential distribution of AMPA-receptor subunits in the tectofugal system of the pigeon. Brain Res. 785; 114-128.

This is an open access article distributed under the Creative Commons Attribution License, which permits unrestricted use, distribution, and reproduction in any medium, provided the original work is properly cited. 